\title{
REMOTE SENSING FOR CROPS IDENTIFICATION
}

\author{
Escobar González José Luis* \\ * Field Operations Planning Coordinator, Census and Agricultural Surveys Department, INEGI, \\ Aguascalientes, Mexico, jose.escobar@inegi.org.mx
}

\section{Commission III, WG III/10}

KEY WORDS: INEGI, Remote Sensing, Crop Surface Estimation, Satellite Image, Data Collection, México.

\begin{abstract}
:
Since 2012, the INEGI began using satellite images to identify crops and to be able to locate areas where they develop. To date, this activity has been developed as a research project in which different multispectral images and different tools for the processing of satellite images have been used. Supervised classification techniques have made possible to identify the surface of some important crops of annual cycle and some perennials, such as sorghum, corn, lemon, grape, potato, orange, among others. The use of this methodology allows exploring new ways of obtaining agricultural statistical information, as well as generating statistical data that can be used to validate or confirm crop coverage at specific places. To put this project into practice, after the initial investigations, we trained a small group of people, with whom we carried out some tests to know and evaluate the benefits or disadvantages of applying identification of crops through remote sensing. Between 2012 and 2018, INEGI has received support from institutions that are more advanced in the use of remote sensors, such as NASS from the USA, StatCanada and JRC of the European Union. Tests designed by INEGI have run on sites with different topographic and climatic conditions to better understand the spectral response of crops. This document presents some of the main results obtained.
\end{abstract}

\section{BACKGROUND}

Although INEGI has been working with satellite images from the 1970s, it is since 2009 that the Institute specifically investigates the methodology for estimating the area of crops through remote sensing. During this research we have found out that there are some organizations like the NASS (National Agricultural Statistics Service) of the United States Department of Agriculture, the StatCan (Statistics Canada) of Canada and the JRC (Joint Research Center) of the European Union, were already working whit satellite images to generate information in support of agricultural statistics. We also:

- Met the minimum requirements of software, computer equipment and personnel training to start a project of this nature.

- $\quad$ Formed a working group that was self-trained on this methodology.

- Had self-training sessions using INEGI's stock images, where we learned to classify items.

- Visited our colleagues from StatCan, JRC and NASS to learn about their processes and solve doubts.

- Organized a national seminar on remote sensing for crop classification, which was hosted by a JRC specialist.

During 2012 we tested the methodology without spending resources on images by using 2007 and 2010 files, to know the feasibility of generating data on crop surfaces with SPOT 5 . In order to collect the field samples we asked the farmers about their crops grown during those years. To this end, we held activities such as:

- Obtaining inputs to plan the project.

- Preparation of personnel to collect the data.

- Planning of the field project in the Aguascalientes Valley, Mexico.

- Data collection in the field.

- Processing of the satellite images and data generation.
As a result, it was possible to obtain the percentage of land occupied by each crop in the selected area, which was similar to the official data generated by SAGARPA ${ }^{1}$, in turn, it was possible to generate the documentation that was called Result of the Analysis of Crops Zones with Satellite Images (INEGI et al 2012). Due to this test we faced an important advance in the project and decided to perform tests using current images (where the crop is observed and still standing when visiting the land).

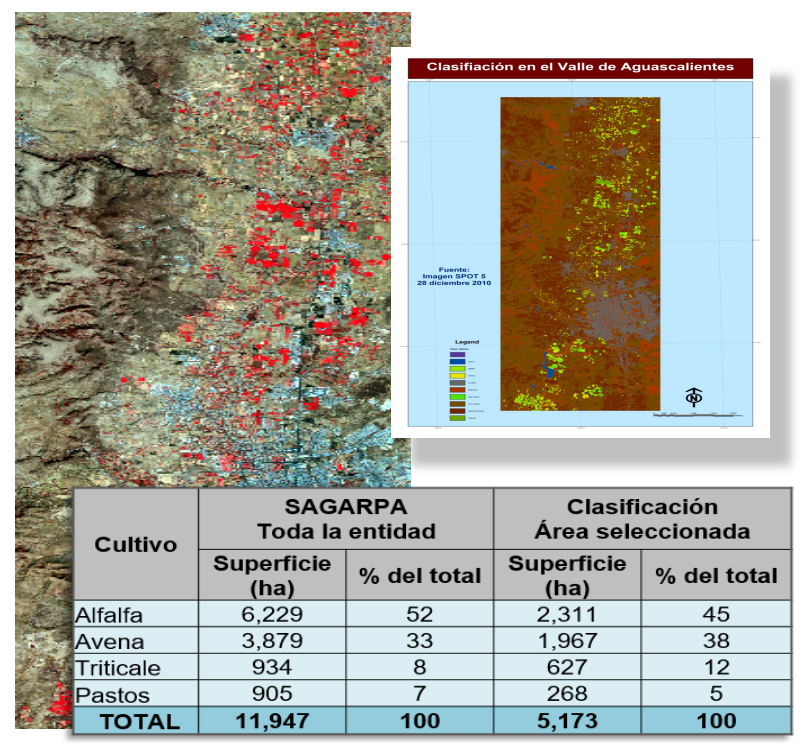

Figure 1. Results obtained by SAGARPA and INEGI.

\footnotetext{
1 Ministry of Agriculture, Livestock, Rural Development, Fisheries and Food (SAGARPA for its acronym in Spanish).
} 


\section{ACTIVITIES SUMMARY \\ 1.1 Year 2013}

In 2013, our purpose was to apply and test the methodology using current images, with coverage of full politicaladministrative areas, called municipalities (to be able to compare with other sources that publish results at the municipality level). Thus, a test was carried out with an annual crop (sorghum) in flat terrain, in a state of the country with important production. This process involved activities such as:

- Selection of municipalities with high sorghum production in the state of Guanajuato, Mexico.

- Image purchase process to study sorghum.

- Planning, and data collection in the field and processing of the RapidEye satellite image (when studying sorghum in the field, vegetable plantations were found, from which data were also collected).

These activities resulted in obtaining sorghum and vegetables surface in 5 municipalities and the creation of the document called Project of identification of crops with satellite image (INEGI et al., 2013). An important finding was that for vegetables it was not possible, using this method, to estimate the planted area, due to its very short cycle development, because when we visited the lands they had already been harvested; due to this, we proposed to repeat the sorghum exercise in 2014 , to have comparable data.

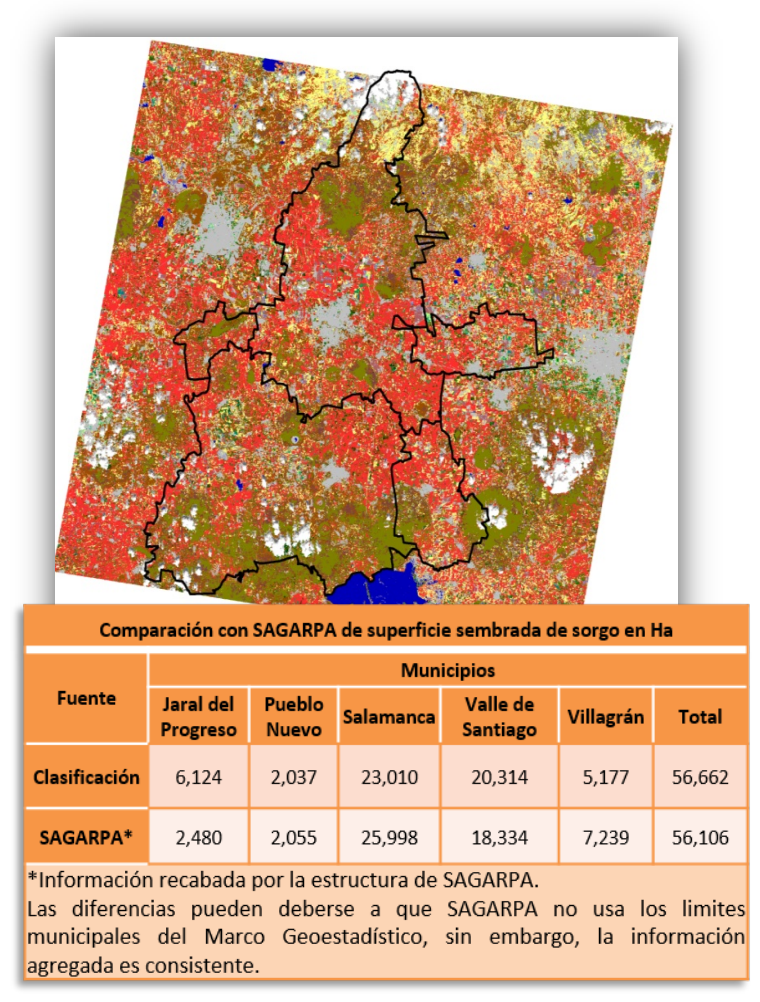

Figure 2. Results obtained by SAGARPA and INEGI.

In 2013, some data generated from the National Agricultural Survey (ENA by the acronym in Spanish) 2012, was also verified, with the purpose of obtaining surfaces of potato and rice of some country's areas and compare the results to know the differences between the ENA and official data; for this, RapidEye images were used. In all cases, the results of the estimation of potato area were similar to those generated by the ENA 2012. Regarding rice, the floods presented in that year caused confusion between flooded grasses and land with rice, so it was impossible to estimate the surface. However, in the field work for sampling, we found a significant decrease in the number of plots that were dedicated to rice cultivation, which generates the hypothesis that there was a decrease in the area of that crop.

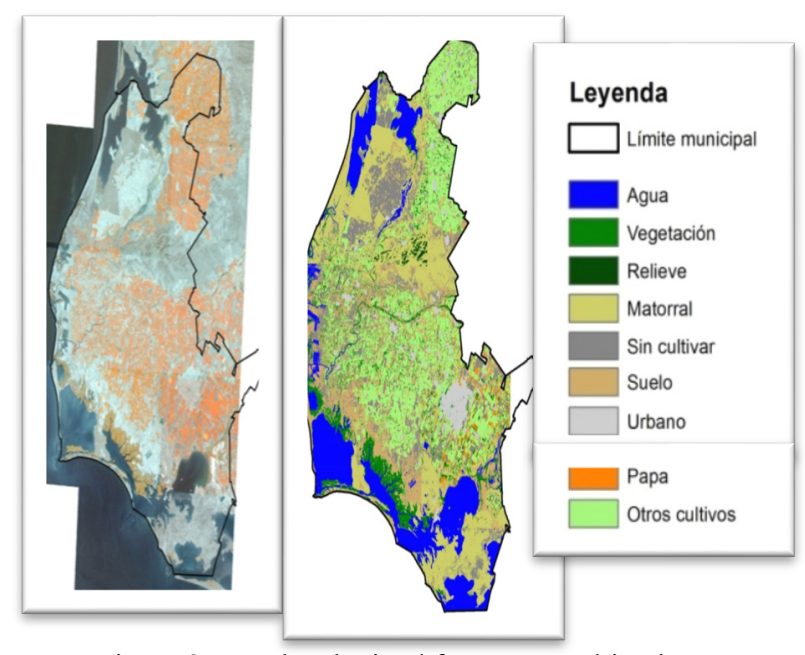

Figure 3. Results obtained for potato cultivation.

\subsection{Year 2014}

During 2014, the exercise was repeated in the state of Guanajuato, Mexico, to establish sorghum as a test crop. In addition, it was planned to apply this methodology in perennial crops, present in areas of rugged orography and exuberant vegetation, using current images. The activities carried out were:

- Selection of municipalities with high production of sorghum in Guanajuato and lemon in the state of Colima.

- Image purchase process.

- Planning, data collection in the field, processing of RapidEye satellite images and obtaining lemon surfaces in Colima and sorghum in Guanajuato.

Once these activities were concluded, the following results were obtained:

- The area obtained from sorghum was consistent with that generated in 2013 .

- The lemon surface and other crops were obtained in 4 municipalities.

- The abrupt terrain, the abundant wild vegetation and the combination of crops generated difficulties in the field work and during the processing of the image for the separation of crops.

- The conclusion in the case of lemon is that in these conditions it is not advisable to use the method to estimate surfaces.

- With such results, it was proposed to test, in 2015, the method in areas with semi-desert climate, mixed orography and continue with the test crop in Guanajuato.

In this year, we attended a meeting in which we exchanged experiences with the NASS and StatCan, 
From this event a report was generated detailing the activities carried out (INEGI et al., 2014); Documentation was also generated with the results obtained in the tests conducted in Guanajuato for sorghum (INEGI et al., 2015a) and lemon in Colima (INEGI et al., 2015b).

Year 2015

In this year the Guanajuato exercise was repeated in order to generate comparable historical information on sorghum. Another purpose was to apply and test the methodology in arid zones, of mixed orography (plain and hills) for a deciduous perennial crop, using current satellite images.

To achieve this, the following activities were carried out:

- Selection of areas with high production of sorghum in Guanajuato and grape in the state of Baja California, Mexico.

- Image purchase process.

- Planning, data collection in the field, processing of RapidEye satellite images and obtaining of surfaces, for sorghum, grapes and other crops as a collateral result.

Resulting from these activities, we found out that the surfaces obtained from sorghum were consistent with those generated in 2013 and 2014, both in value and in trend (there is a downward trend in the sown area). In the same way, the grape surface and other crops in the selected areas were obtained. There were difficulties of separability during the processing of the image, due to the different ways of planting the grape, however, the results were consistent with other sources of information.

The tests conducted in the Guanajuato State, during the years 2013, 2014 and 2015, allowed to compare the results from each year and each institution, as shown below (Figure 4):

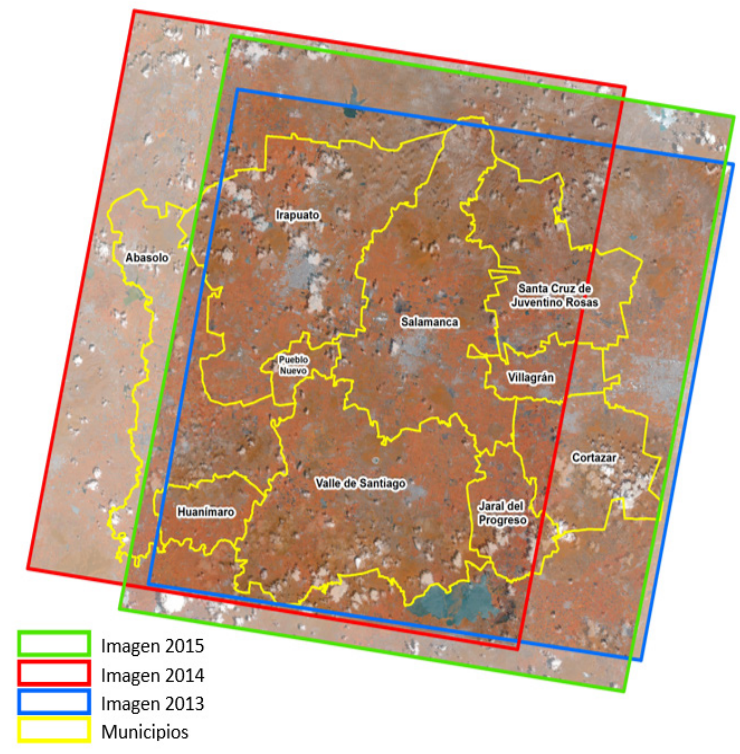

Total municjpjos comparables (ha) Alio Clasjificación SAGARPA Diferencia

\begin{tabular}{|l|l|l|l|}
\hline 2013 & 50,348 & 52,731 & 2,383 \\
\hline 2014 & 46,041 & 49,806 & 3,765 \\
\hline 2015 & 41,527 & 36,061 & 5,466 \\
\hline
\end{tabular}

Figure 4. Results obtained by SAGARPA and INEGI

The results of the classification throw a downward trend of 4,400 hectares per year between 2013 and 2015, a situation similar to that reflected in SADER information.

As a result of the field tests for both Guanajuato and Baja California, the respective documentation was generated but this until 2016 (INEGI et al 2016a and INEGI et al 2016b).

During 2015 we participated in a satellite image processing workshop, organized by NASS, in which we learned about the type of processing that this institution uses for the images. It was determined that the methodology used by INEGI is based on the inputs it has and that it was not feasible to apply the processing as the NASS does. As evidence of attendance at this event, a detailed report is generate on the activities carried out in it (INEGI et al., 2015c).

\subsection{Year 2016}

For this year, the purpose was to apply and test the methodology in 10 different zones of the country, to involve and train INEGI's staff in different offices in the country, for which areas and crops with diverse orographic and climatic characteristics were selected. For this, a joint work was carried out between the geographic and statistical areas of INEGI, highlighting the following activities:

- Selection of zones and crops.

- Image purchase process.

- Hiring and training of personnel.

- Planning and data collection in the field,

- RapidEye satellite image processing and surface acquisition.

Once these activities were carried out, the area of the crops in the selected areas was obtained, which is consistent, in most cases, with the official data generated by the SAGARPA.

Two zones of the center of the country presented the biggest difference in comparison with the official data, due to the fact that the orange, mandarin and lemon crops were grouped in the estimation or that, at the time of obtaining the sample, most of the land had been harvested.

\subsection{Year 2017}

For this year, the review and analysis of the results obtained in 2016 was made prioritizing the areas with the greatest difference with respect to official statistics. As a result, we had to reprocess the images of one of the zones (north of the country), due to a low evaluation of the statistical values. Reprocessing yielded new data which were consistent with official statistics.

\section{METHODOLOGY FOR ESTIMATING CROP SURFACES THROUGH REMOTE SENSING}

\subsection{Selection of areas}

The selection of study areas was determined according to the crop to be tested in those zones where we found higher concentration levels. To do so, we selected municipalities with the largest sown areas, which we detected thanks to different sources of information available like SAGARPA 2017. 
The space had to be bounded by the geographic coordinates (latitude and longitude) extreme (in degrees, minutes and seconds), that gave coverage to the selected municipalities, because these were taken as the basis to obtain the image that was required. Thus, the geographic design of each project can be an area, a municipality, several municipalities or a state.

\subsection{Selection of sample points}

The methodology does not pose using a rigorous statistical design to select areas and sample terrains. The land selected to obtain field information (sample) is made independently for each image, based on a mesh of equidistant points plotted on the image (Figure 5, Gallego, 2013), and selecting the points that, according to the analyst's experience, their knowledge of the different tonalities in the image and census data available, reflect vegetation in general and the crop under study.

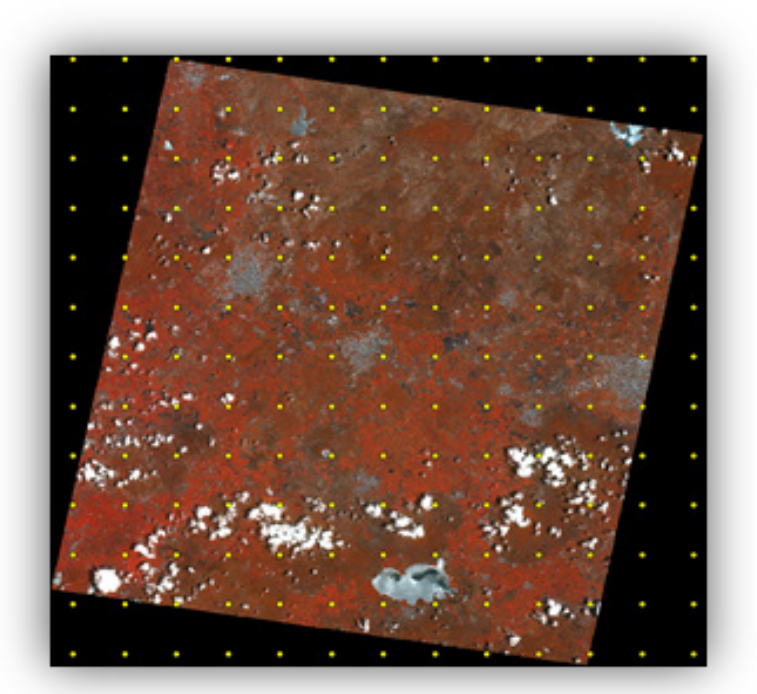

Figure 5. Mesh of resulting points for a sample

\subsection{Stages of the methodology for estimating crop areas through remote sensing}

The statistical and geographical INEGI's departments determined to estimate the crop area by remote sensing must perform the following activities:

- Definition of areas / crops of interest.

- Request for satellite images.

- Revision of the requirement and determination of feasibility.

- Acquisition and reception of satellite images.

- Selection of the sample to obtain information on field crops.

- Review of the selection of the land to obtain field information.

- $\quad$ Field project planning.

- Execution of field activities to obtain information of the terrains shown.

- Processing of satellite images.

- Evaluation of the results of the process.

- Calculation and analysis of surfaces obtained from the classification.

- Comparison of the results of image processing with other sources.

- Project evaluation.

\section{CONCLUSIONS}

As a result of the remote sensing work carried out to identify crops, INEGI has reached the following conclusions:

- During the tests performed, two main obstacles were faced: the cost of the images and high cloudiness in the cultivation areas.

- Now we know that the cost of images is no longer a problem, because different institutions make them available to users, free of charge, through the Internet.

- Regarding cloudiness, it can be said that there is a change in the approach to take advantage of information from satellite images, which allows us to use new tools such as the data cube, with which images without clouds or with a degree of cloudiness that does not affect the development of projects.

- The methodology has been applied to estimate sorghum, grape, potato, corn, plantain, forage oats, lemon, rice, wheat, beans, nopal vegetables and oranges; of these, the first five have presented the best results in terms of their classification to estimate the surface.

- The method is not recommended for estimating vegetable surfaces, neither for lemon that is grown in combination with other crops, nor for intercropping.

- Data collection in the field is complicated in areas where rainfall is abundant during the crop development cycle, or in crops that require abundant water.

- The method generates information that can be used to verify census and agricultural surveys data, which ensure the quality of crop area data.

- Each test has generated information to update the Agricultural Census Framework in Mexico, in terms of the crop present in the lands that are part of the processed image.

- We have not applied the method in complete entities or large regions, where diverse physical and climatic conditions coexist or in places with an important presence of crops.

- Executing this type of projects implies the collaboration between different institutions of the country.

To support the previously written, a methodology was created for the subsequent projects (INEGI et al., 2016c).

\section{REFERENCES}

INEGI, DCEA, 2012. Resultado del Análisis de Zonas de Cultivos con Imágenes de Satélite.

INEGI, DCEA, 2013. Proyecto de Identificación de cultivos con imágenes de satélite. Informe del uso de la imagen de satélite RapidEye 2013-09-30T181745 RES 1B-NAC 14164775170081

INEGI, DCEA, SICCC, 2014. Informe de comisión para participar en la reunión técnica del grupo de sistemas de información geográfica y percepción remota del Comité Tripartita de Norteamérica en Estadísticas Agrícolas NATCAS.

INEGI, DCEA, 2015a. Pruebas de Identificación de Cultivos con Imágenes de Satélite en Guanajuato, 2014. 
INEGI, DCEA, 2015b. Pruebas de Identificación de Cultivos con Imágenes de Satélite en Colima, 2014.

INEGI, DCEA, 2015c. Informe de comisión para participar en la sesión de entrenamiento del grupo de sistemas de información geográfica y percepción remota del Comité Tripartita de Norteamérica en Estadísticas Agrícolas NATCAS en la metodología para generar el Cropland Data Layer.

INEGI, DCEA, 2016a. Pruebas de Identificación de Cultivos con Imágenes de Satélite en Guanajuato, 2015.

INEGI, DCEA, 2016b. Pruebas de Identificación de Cultivos con Imágenes de Satélite en Baja California, 2015.

INEGI, DCEA, 2016c. Metodología Utilizada en las Pruebas de Identificación de Cultivos con Imágenes de Satélite.

J. Gallego., 2013. MARS AGRI4CAST

Mass SAGARPA, 2019, Avance de siembras y cosechas. http://infosiap.siap.gob.mx:8080/agricola_siap_gobmx/Resume nProducto.do 